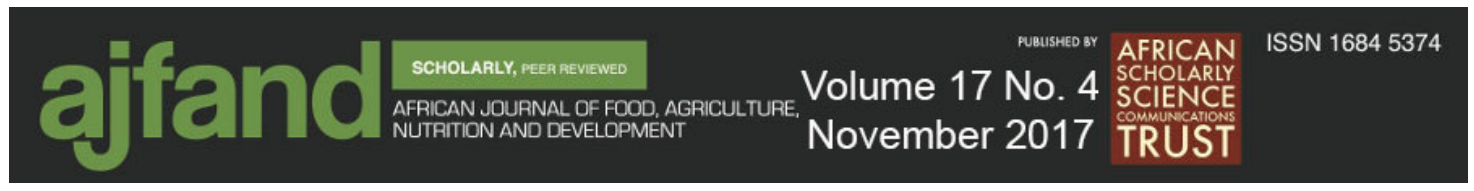

\title{
CONSUMERS' VIEWS AND USE OF LABELS ON FOOD ITEMS SOLD IN BULAWAYO URBAN PROVINCE, ZIMBABWE
}

*Ncube, $\mathbf{T}^{1 *}$, Makurunje $S,{ }^{1}$ and $S$ Dube ${ }^{1}$

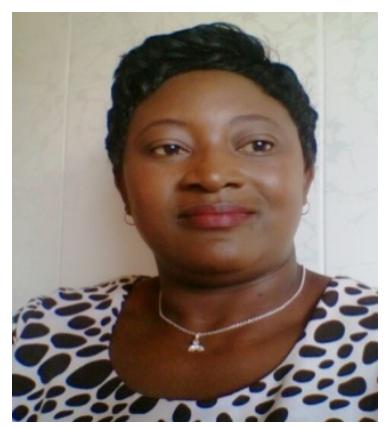

Thembie Ncube

*Corresponding author email: thembekile.ncube@nust.ac.zw

${ }^{1}$ Department of Applied Biology and Biochemistry, National University of Science and Technology. P Bag AC 939, Ascot, Bulawayo, Zimbabwe 


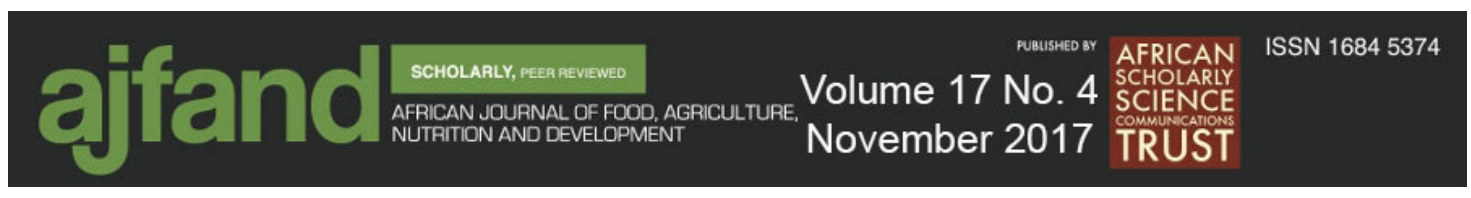

\begin{abstract}
Food labels are a medium by which consumers acquire knowledge about packaged foods they are considering to purchase. The label makes the first impression about a product and has a great effect on the purchasing decision for consumers. In recent years, literate consumers have become interested in nutritional issues. Lifestyle, age, dietary and safety concerns have been the contributing factors to nutritional awareness by consumers. Nutritional labels can generally have a positive impact on food consumption and may save health-care costs for those consumers with health concerns. On the other hand, for those consumers who are illiterate, price may be more important in making purchase decisions. This study intended to investigate how consumers in Bulawayo Urban Province (Zimbabwe) view and use labels on packaged food items. Seventy-five randomly selected consumers were questioned about their perceptions, attitudes and use of label information using open ended structured questionnaires. The consumers were selected on the basis of being present at the supermarkets at the time of sampling. The respondents were interviewed at different times of the day to cater for employed and unemployed people. The results obtained indicate that the extent to which food labels are used depends on factors such as price of food products, individual health needs and gender. For consumers who use food labels to make their purchase decisions, not all the information on the label is considered. Items on the labels to which the consumers responded were brand, nutritional profile and mass of product in relation to the price. The label elements which were extensively used by consumers in this study are date mark $(81.3 \%)$, weight of food $(89.3 \%)$ and price (77.3\%). The least used element is the nutritional panel $(50.7 \%)$. About $44 \%$ of the consumers were not sure about the trustworthiness of the information given on food labels. Food labels are important to a greater extent for people with special dietary requirements, while the remainder of the studied population are influenced by price in their purchase decisions. Consumers seem not to understand some of the information on the food labels because of the difficulties in interpreting what is written.
\end{abstract}

Key words: Consumer, packaged food, labels, nutrition, nutritional panel, perceptions, purchase, behaviour 


\section{INTRODUCTION}

Literate consumers have become increasingly interested in nutritional issues over the last few years. Interest in nutrition has been driven by factors such as lifestyle, ageing, dietary and safety concerns $[1,2]$. However, a number of factors such as economic, household income and price of goods determine the choice of food and consumer attitude in the consumer selection process [1].

For a consumer buying packaged food, the label is the single most important resource because it contributes to their first impression about the product and communicates information that helps to make a purchase decision $[3,4,5]$. Labelling is a legal requirement in most countries and is defined as a written, printed or graphic matter on an article or any of its container or wrappers $[6,7]$. The label may take different forms, from a simple tag attached to the product to a complex graphic design that is part of the package. Labels list the essential information such as ingredients and quantities, describe features, give instructions, explain benefits and deliver advisories and warning information. Information considered being critical to health and safety is mandated globally by standards associations to appear on the label [4].

In Zimbabwe, the Standards Association has its own specific requirements about food labels, which are specified according to the Food Standards (Food labelling) regulations [7]. Nutrition labelling is intended to inform the consumer of nutritional properties of a food and consists of nutrition declaration and supplementary nutrition information. The bill clearly states that pre-packaged food shall not be described or presented on any label or in any labelling manner that is false, misleading or deceptive or is likely to create an erroneous impression regarding its character in any respect. The specific requirements are with regards to a number of factors which include what the food is made from, preservatives and artificial flavouring in the food, best before date and the nutrition information that should be declared on a label [8].

Food label information assists the consumer to better understand the nutritional value of food and enables them to compare the nutritional value of similar food products as well as to make healthy and informed food choices [9]. Food labels should be clear and understandable to assist consumers to make a better informed food and dietary choice. Purchase decisions driven by hunger limit the freedom of choice as well as the safety concerns for consumers [10].

The amount of material that can be incorporated into a label is limited by the label's size and by the ability of the consumers to absorb information. In stores where a number of products compete for consumers' attention, labels must be effective signals. None of the information on the labels can accomplish anything if consumers do not notice the product and consider the suitability for their purposes [11]. Unnecessary information should be avoided by label designers so as not to confuse consumers and draw criticism from them. A fundamental challenge facing the food manufacturers is labels that effectively communicate the information that matters most to the consumers. Recently there has been a change from grid or table nutrition information which appears at the back of the product to simplified nutrition labels that appear on the front 


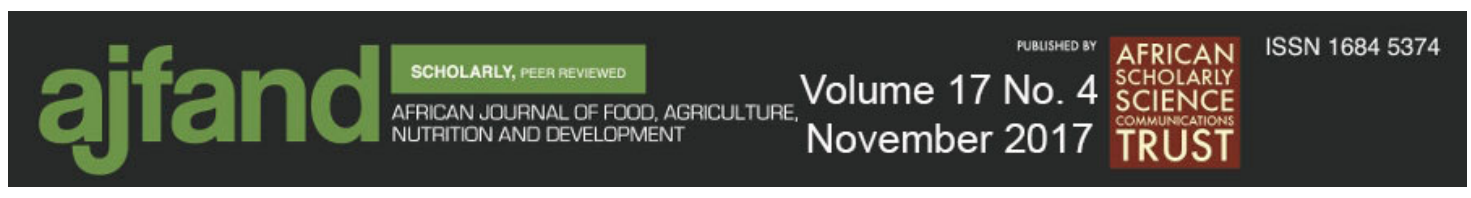

of the pack, often called front-of-pack (FOP) sign positioning information. This type of label endeavours to highlight essential information that a consumer needs to know when purchasing the product [12]

Previous research indicates that nutritional labelling and nutrition information can alter consumer behaviour by having a positive impact on food consumption patterns and save healthcare costs [9].The effectiveness of a label depends on the consumers' perceptions and beliefs about the use of these labels. When faced with a purchase decision, consumers generally adapt strategies that are contingent upon the perception of the decision environment. For example, if the consumers do not perceive or believe that the nutrition information on the food labels is useful to them, they are less likely to use labels. Understanding the type of consumers who have these perceptions and beliefs as well as the factors that influence these perceptions and beliefs is crucial for designing effective food labels. Consumer perceptions and beliefs have long been found to be predictors of behaviour [13].

The effectiveness of certain types of nutritional labels may be limited. Consumers must be able to process information that is given on a food label. This may suggest that labels requiring calculations on the part of the consumer may not be useful [14]. It has been noticed that a strong interest in nutritional labels does not necessarily indicate an understanding of the quantitative information. Shoppers may be influenced into buying a product simply by the qualitative information given on a label. Other researchers have found important factors that motivate buyers in their purchase choices for pre-packaged foods are price, nutrition information and taste especially in the less literate populations $[7,14]$. Influencing factors may be affected by demographic factors such as age, gender and education. Older consumers are perceived as less capable in processing large amounts of data than their younger counterparts. Higher levels of education lead to increasing levels of information search. A recent find indicates that males are less likely to use food labels than females. Females find risk reducing search strategies more useful than males [15].

In the recent years, health concerns are gaining much cognisance for consumer food choices. Results from 15 countries in the European Union (EU) indicate that health is one of the five main attributes for consumers when buying food products [2]. The consumer food choices are also strongly influenced by quality of the food, sensory attributes, process attributes and convenience attributes. The nutritional panel and the 'light' claim helps consumers to assess the health attributes of food products. The nutritional panel usually provides the more detailed information about the health characteristics of the product while the claim gives an indication about one specific nutrient $[2,16]$.

Not much information is available on the factors that influence consumer beliefs, perceptions and behaviour in Zimbabwe. This study was to, therefore, attempt to fill the gap about consumers' awareness, knowledge and behaviour in relation to food labelling. 


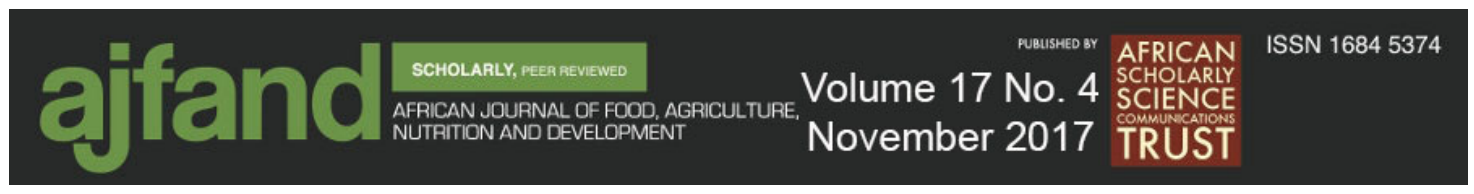

\section{METHODS}

The study was based on 75 randomly selected individuals who were from nonprobability shops and supermarkets in the Bulawayo Central Business District. The respondents were selected on the basis of their being present at the supermarket or shop at the time the field workers were conducting the interviews. The interviews were carried out at different times of the day to cater for the employed and unemployed populations. The ages of the respondents ranged from 18-69 years, comprising 45 females and 30 males.

Data were collected over six months from willing respondents by face to face interviews using a questionnaire, which was designed to establish situational, attitudinal and behavioural characteristics of the respondents to food labelling. Individuals responded to questions about their awareness of label information, frequency of label use and reasons for checking labels as well as trustworthiness of the label information. Some of the questions were divided into sub-sections and both openended and closed questions were used. Questionnaires were analysed using descriptive statistics (frequency distribution graphs) and inferential statistics (chi-square statistics).

\section{RESULTS}

Of the 75 people interviewed, 11 females and eight males had special health needs which included such conditions as: hypertension, diabetes, allergies to food, pregnancy and lactation, religious and ethical beliefs as well as vegetarianism.

\section{Awareness of label information}

Figure 1 shows that the consumers generally had a good idea about the type and amount of information found on food labels. Some of the information was registered in the consumer's memory from previous purchases and hence consumers had no need to read the labels the second time around. 

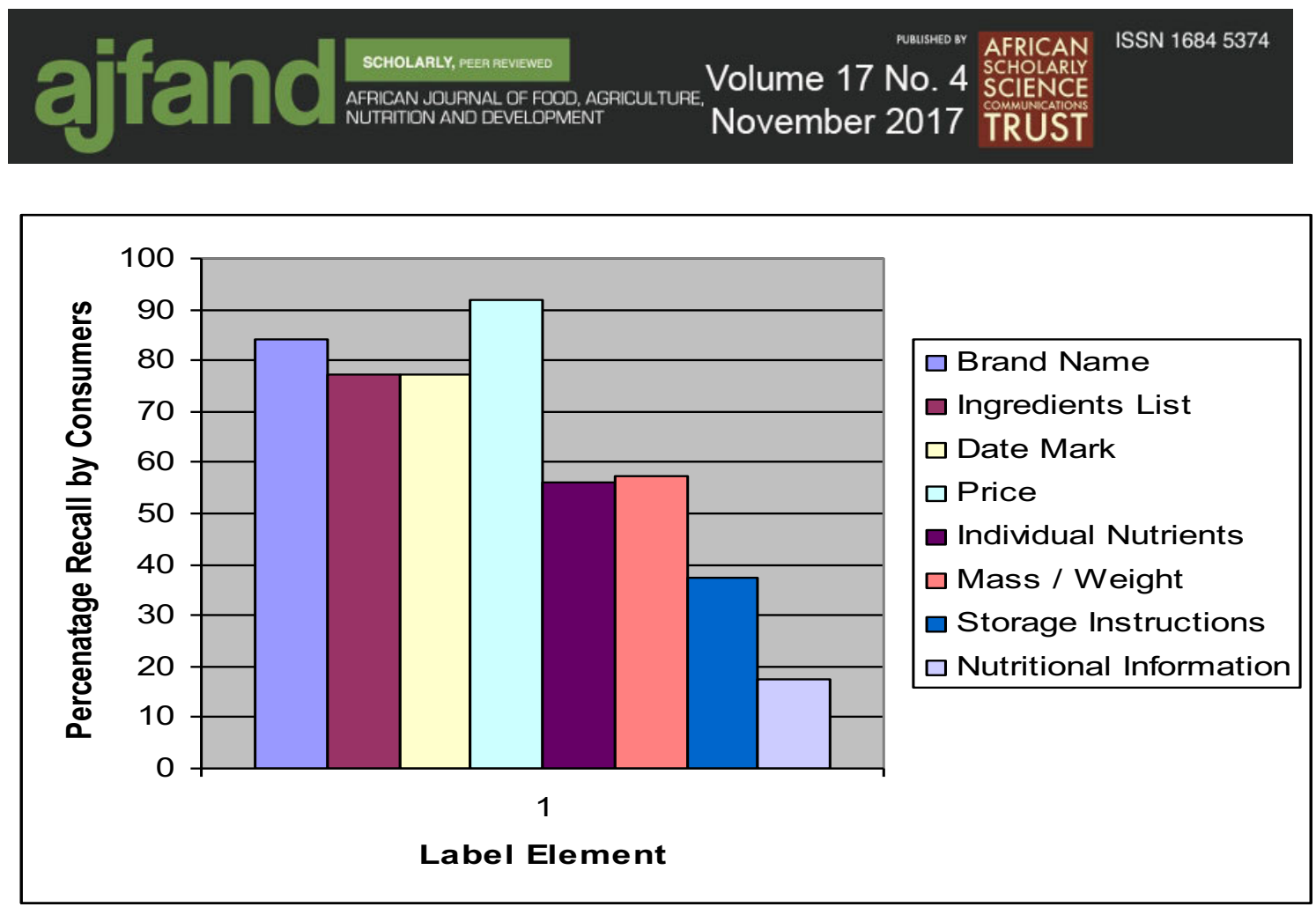

Figure 1: Unprompted awareness of label elements by consumers surveyed in Bulawayo Urban Province

\section{Frequency of Label Element Use}

Consumers generally expressed that they read food labels as and when they needed to. Thirty-seven percent of the consumers indicated that they used the ingredients list only occasionally while $10 \%$ indicated that they never used it, and $23 \%$ used it most of the time (Figure 2).

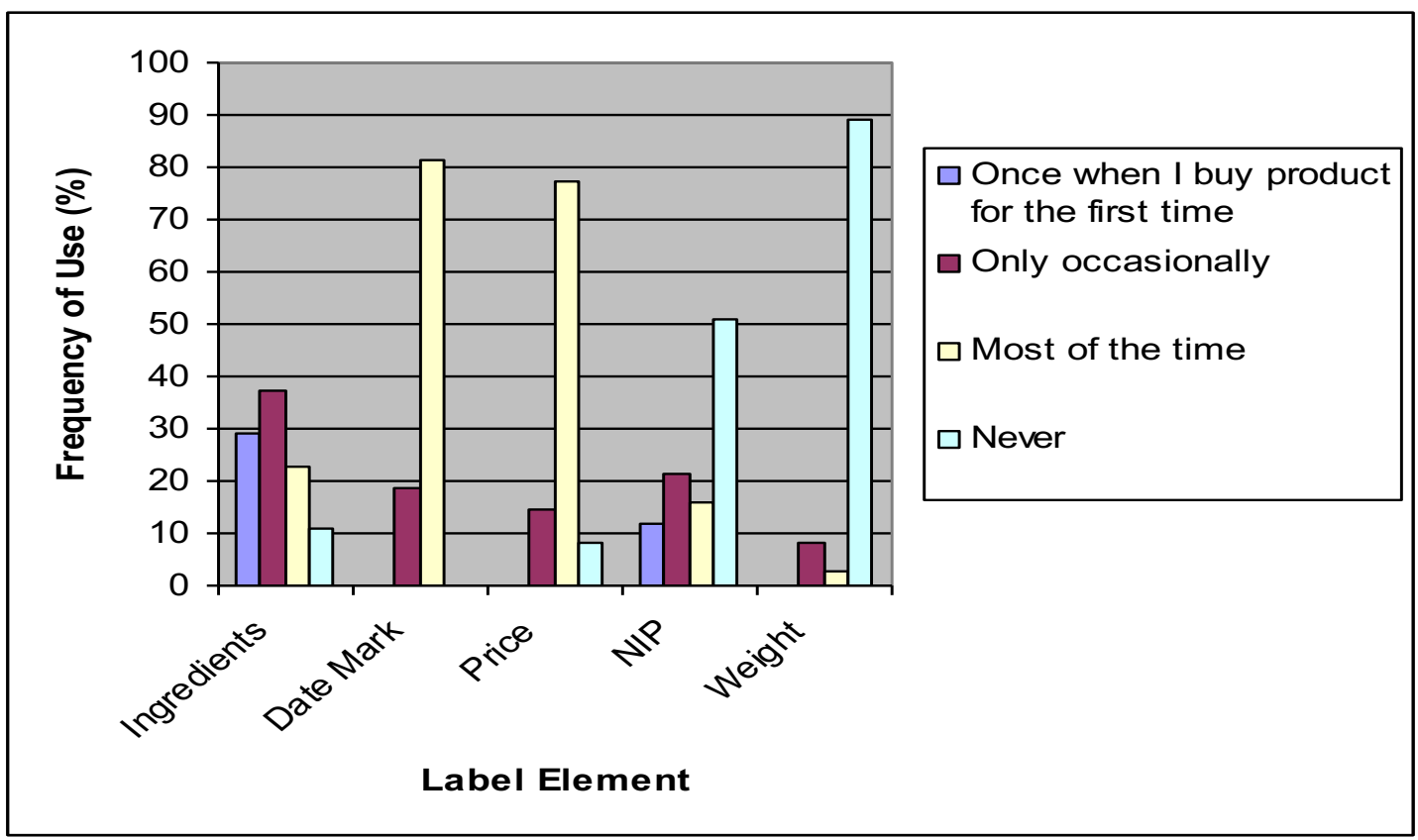

Figure 2: Frequency of label element use by consumers surveyed in Bulawayo Urban Province. NIP represents the non-nutritional panel 


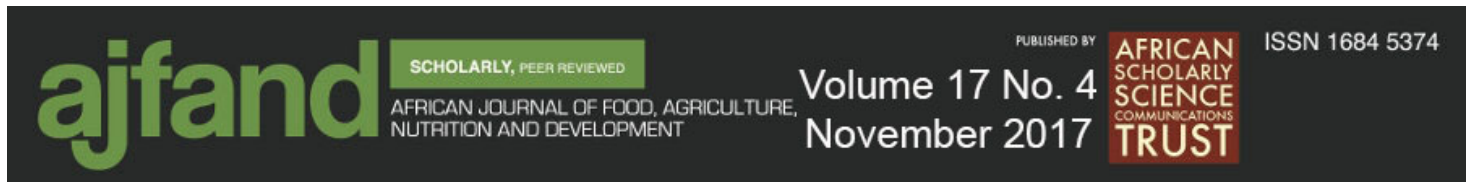

Frequency of label element use appears to be gender-sensitive as shown in Figure 3 and the chi-square test confirms that frequency of label element use is dependent on the sex of the consumer. Generally, the females make use of the label element when purchasing packaged foods.

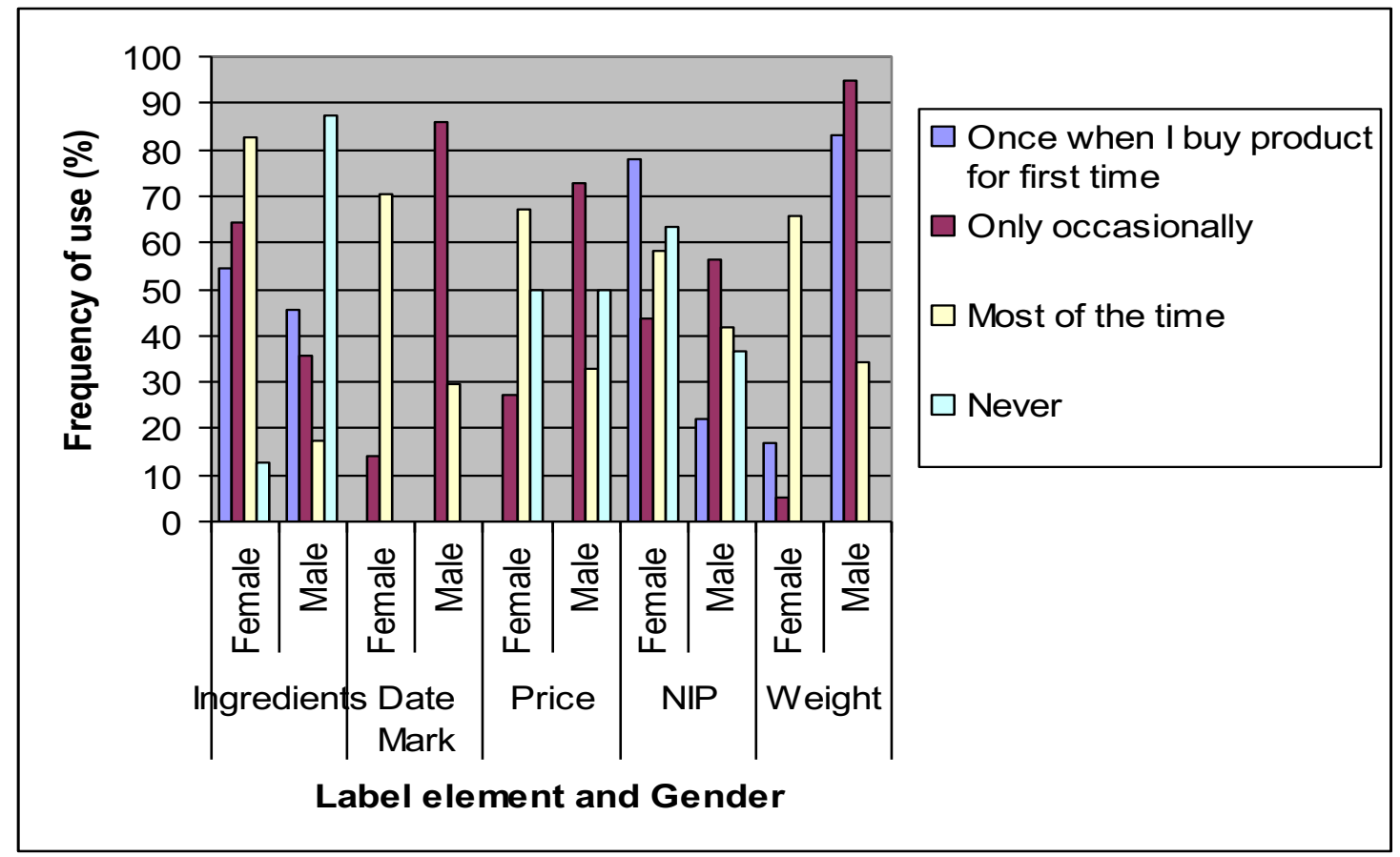

Figure 3: Gender sensitivity toward label element use in Bulawayo Urban Province. NIP represents the non-nutritional panel 


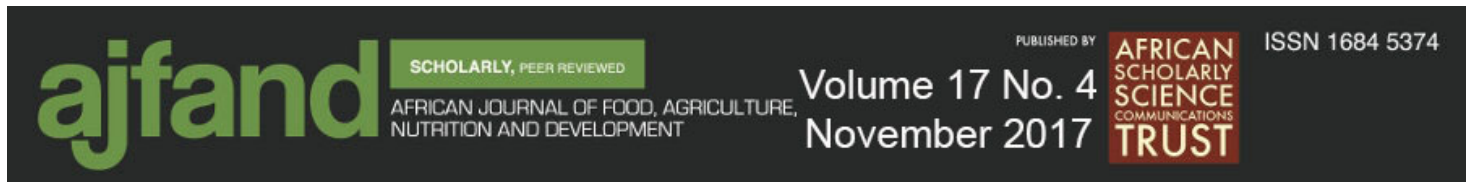

Of the consumers who indicated that they used the ingredients section most of the time, $23 \%$ had special health needs as indicated in Figure 4.

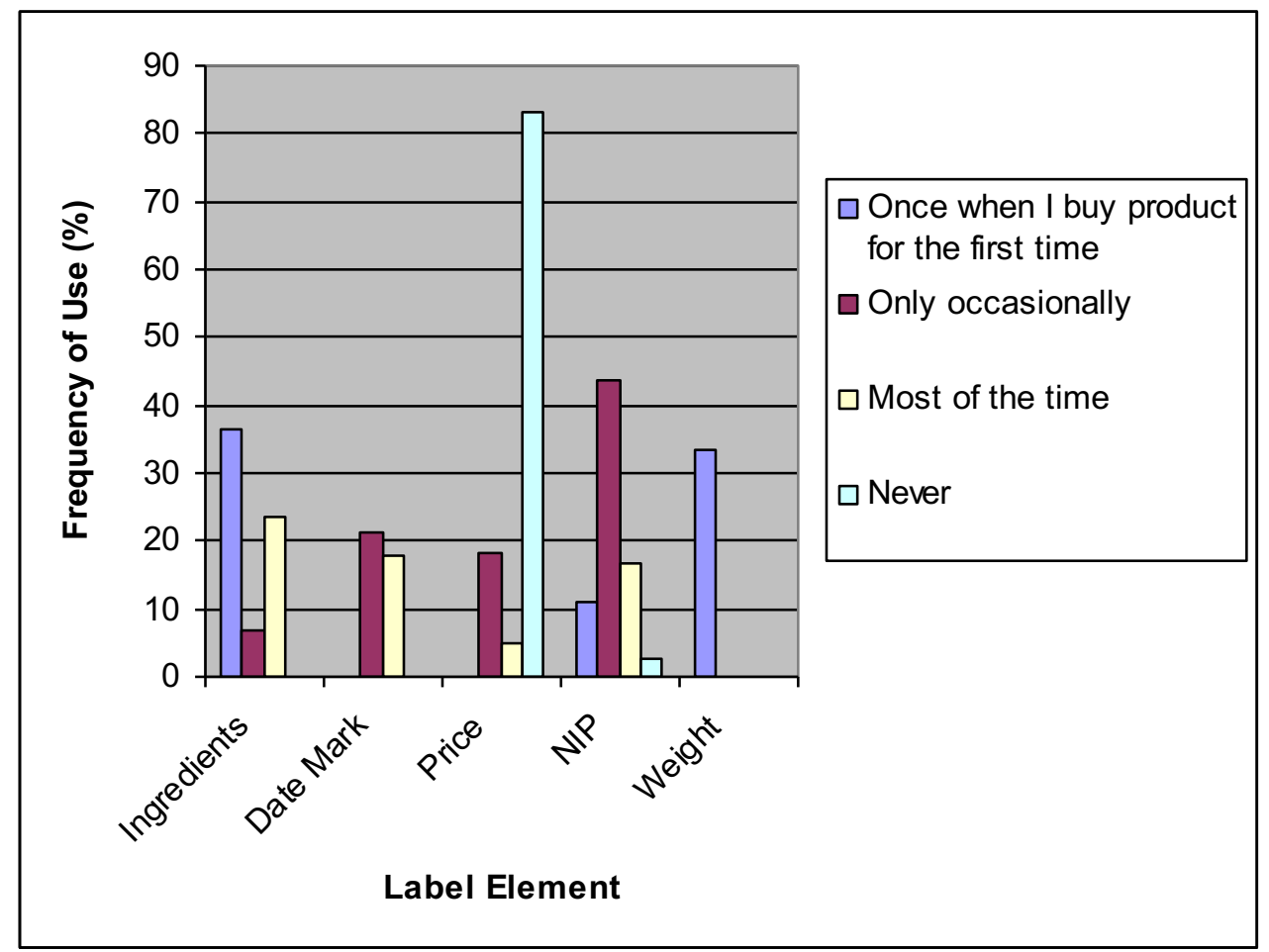

Figure 4: Frequency of label element use by people with special needs in Bulawayo urban province. NIP represents the non-nutritional panel

\section{Trustworthiness of label information}

Forty-four percent of consumers surveyed in this study were not sure whether to trust label information or not as indicated in Figure 5. 

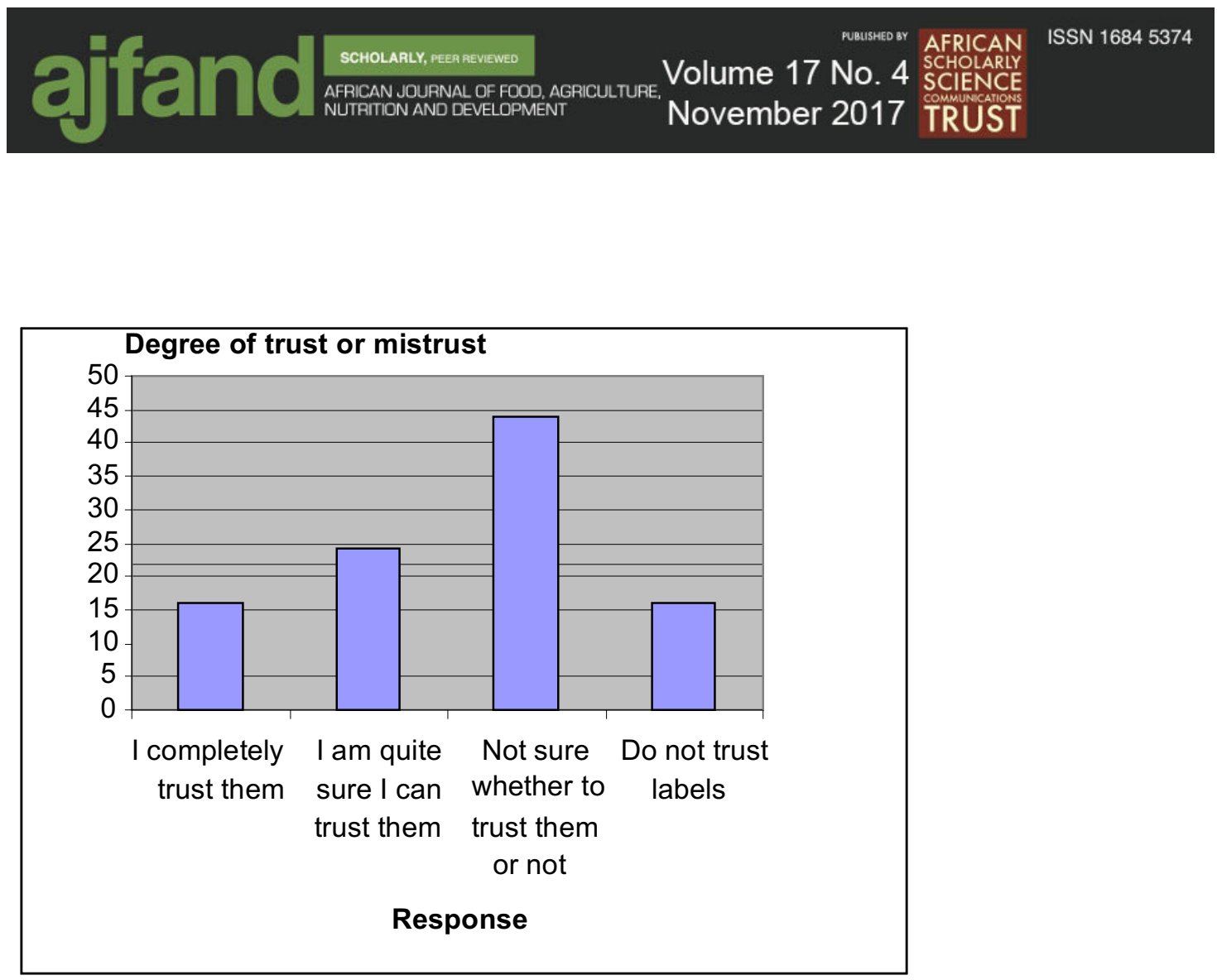

\section{Figure 5: Trustworthiness of label information as perceived by consumers surveyed in the Bulawayo Urban Province}

\section{DISCUSSION}

The consumers could recall label elements such as brand name, ingredients list, storage instructions and the date mark. Figure 1 indicates that the price of the product plays a critical role in determining food choice. For some consumers, price is an indicator of quality. In a survey carried out in the United States, many consumers indicated that quality was the most important factor they considered when purchasing food and are willing to pay higher premiums for what they consider to be of better quality [17]. This is contrary to the results obtained in this survey; however, it is expected, considering the harsh economic conditions in the country at the time of the survey. There was a fairly low level of recall of the nutritional information panel (17.3\%). There is also a contradiction to the results obtained by the Consumer Association (CA) survey where $89 \%$ of the consumers interviewed indicated that nutrition information is important. The reason for low levels of recall might be that most people in Third World countries are not worried about nutrition because of the limited resources at their disposal [18]. Therefore, what is important to an ordinary consumer in a harsh economic environment as the one being experienced in the country is having something to eat.

From the results in Figure 2, 37\% of the consumers indicated that they used the ingredients list, $10 \%$ never used it while $23 \%$ used it sometimes. In a similar survey carried out by the International Food Information Council in November 2005, 57\% of the people surveyed used the ingredients list most of the time [19]. In a research carried 
out by Food Standards Association of Australia and New Zealand (FSANZ) in 2003, $32 \%$ of the consumers indicated that they used the ingredients list most of the time and $18 \%$ of them used it only occasionally[12]. The little use of the ingredients section in this study can be because of the technical language used. Chemical names are usually used for this section of the food label. This type of language is confusing and does not mean much to the ordinary consumer in a setting used for this survey [19].

Of the consumers who used labels, the majority (81.3\%) indicated that they used date marks most of the time while the remainder used them occasionally. According to the survey performed by the International Food Information Council in 2005, 68\% of the consumers used the expiration dates and the FSANZ found out that $85 \%$ of the consumers interviewed used the date mark [19,20]. A similar study done in Klerksdorp and Potchefstroom regions of South Africa indicated that the date mark is the most frequently used information on the label [21]. The frequent use of the date mark is because date marks are used to determine the shelf life of a food product. Date marks are used as quality indicators, especially for perishable foods and, therefore, consumers use them to buy food that is as fresh as possible. Consumers are also guaranteed that the food will last longer if the best buy date is still far.

Fifty-one percent of the consumers indicated that they never used the nutritional information panel while $12 \%$ used it most of the time (Figure 2). In the Consumer Association (CA) survey carried out in 2003, 89\% of the consumers indicated that nutrition information is important and use it frequently [22]. In Poland, only 15\% of the studied population indicated that they rarely or never paid attention to labels [5]. The apparent discrepancy between frequency of use of nutrition information in this study and the above surveys may be the fact that there is a general belief that having a large variety of foods is an important aspect of a healthy diet [23]. According to the National Heart, Lung and Blood Institute of the National Institutes of Health, USA, over 12.5 million Americans suffer from coronary heart disease (CHD) and more than 500000 die each year, making CHD one of the leading causes of death in the United States of America [24]. This might be one of the reasons for the frequent use of the nutritional label information panel by consumers in the surveys cited above. Of the $12 \%$ consumers who used the nutritional label information most of the time, $16.7 \%$ have special needs. This is contrary to the results obtained by the FSANZ, where $31 \%$ of those who used the nutrition information panel most of the time had special health needs [18]. Reasons provided by consumers for never reading food labels was that consumers tend to purchase food products according to price and habit, while in some cases respondents felt that reading food labels was too time consuming. Taste of a product was generally regarded as being more important than the nutritional content for frequent users of the product [21].

Frequency of label element use was found to be gender sensitive (Figure 3). Most men $(88 \%)$ indicated that they never read the ingredients list, while the majority of the women $(82 \%)$ indicated that they used the ingredients list most of the time when making their purchase decisions. According to studies done by Nayga [24], there was apparent disparity between purchase behaviours of males and females; that, males are less likely to perceive label information as important. On the other hand, females find 


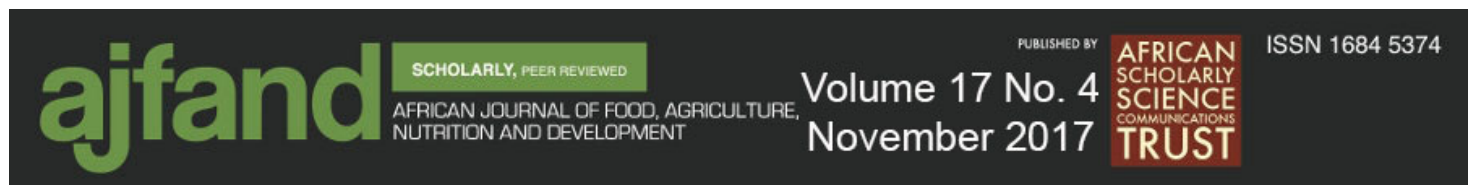

risk reducing search strategies (that is food label use) as more useful than males [24]. A survey carried out by Wandel and Bugge showed that more women $(85 \%)$ used labels compared to $73 \%$ of men [23] which was a significant difference at $95 \%$ confidence level. It has also been found that educated women of a relatively high socio-economic class have a greater awareness of health than do other groups [22].The infrequent label use by males is that when most men do the shopping, they usually buy what is bought by their wives, or what the wives have sent them to purchase and hence no decision making is required. Women, on the other hand, decide the food that will be eaten by the family and, therefore, need to be properly informed about the foods that will be eaten by their families.

Special health needs individuals seemed to use the nutritional panel to some extent as shown in Figure 4.Of the 32\% of the consumers who used the ingredients section, most of the time in the FSANZ survey, 23\% had special dietary needs [19]. According to the chi-square test performed at the $95 \%$ level of significance, there is dependence between frequency of label element and special health needs. These results indicate that the more a person feels that their health is likely to suffer from eating certain foods, the greater the perceived risk. Perceptions of risk then motivate the consumers to read the labels. A study in Poland done in 2010 indicated that $52 \%$ of respondents in the survey are motivated by their health conditions to read labels [5].

Of the consumers surveyed, 56\% indicated that they could trust the label information (Figure 5). Consumers have moved from 'modernization of tradition', which characterized the first half of the $20^{\text {th }}$ century to 'reflexive modernization of industrial society'. While the first is characterized by an unbroken faith in science and progress, the second reflects on the products of modernization, such as un-kept promises, defects or secondary problems. Therefore, safety and risk is directly bound to the concept of reflexive modernization [25] and perceived safety and risk will then reduce levels of trust by the consumers. The results obtained in this study are contrary to those obtained by the FSANZ where the majority of the consumers indicated that they could trust label information [13]. Individuals who could not decide whether to trust the information indicated that they did not understand some of the information carried on labels. Food manufacturers were accused of deliberately using language that could not be interpreted by the ordinary consumer so as to overshadow the negative aspects of the food in order to make profits. It has been noted that poor label comprehension was correlated with low-level of literacy and numeracy skills, thus leading to difficulties in interpreting labels [26].

\section{CONCLUSION}

The results indicate that most urban consumers use food label information at a fairly low extent (37\%). Consumers seem not to understand all the information given on food labels. In spite of this, food labels are an indispensable source of information that is used by the consumers to make their purchase decision. The information that is given on the food label will either influence consumers to buy a certain product or not. Consumers in the rural areas in Zimbabwe, however, usually receive groceries from 


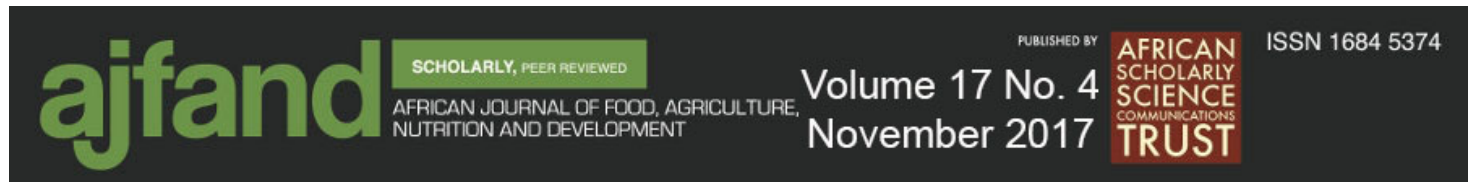

relatives who live in urban areas and, therefore, may not be influenced by the information found on labels.

\section{ACKNOWLEDGEMENT}

The authors would like to acknowledge the Research Board at the National University of Science and Technology, Zimbabwe for funding this research. 


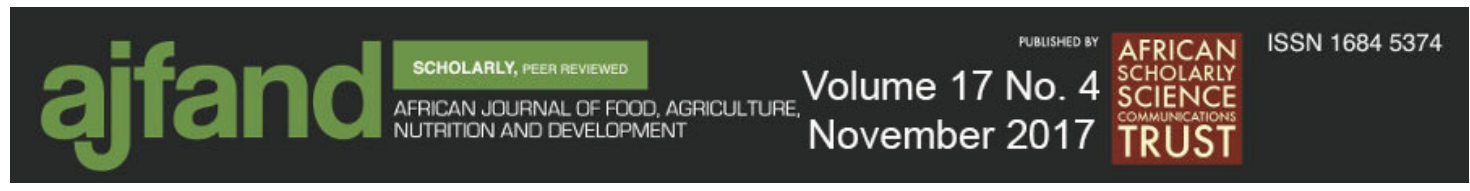

\section{REFERENCES}

1. Shine A, O'Reilly S and K O'Sullivan Consumer use of nutrition labels. Brit. Food J.1997; 99(2): 290-296.

2. Gracia A, Loureiro ML and RM Nayga Consumer' valuation of nutritional information: Achoice experiment study. Food Qual. Pref. 2009; 20: 463-47.

3. Feick LF, Herrmann RO and R Warland Search for Nutrition Information: A Probit Analysis of the Use of Different Information Sources. J. Cons. Aff. 1986; 20(2): 173-192.

4. Bender AE Health or Hoax: The truth about foods and diets. Elvendon; 1986:184.

5. Staniewska K, Pantil HK and M Mieczkowska Contemporary food labelling and its role in consumers' education. International conference on Food Innovation. Universidad Politecnica De Valencia, 2010.

6. Prathiraja PHK and A Ariyawardana Impact of nutritional labelling on consumer behaviour. Sri Lankan J. Agr. Econ. 2003; 5(1): 1- 46.

7. Ababio PF, Adi DD and M Amoah Evaluating the awareness and importance of food labelling information among consumers in the Kumasi metropolis of Ghana. Food Control 2012; 26: 571-574.

8. Food and Food Standards (Food Labelling) Regulations. Statutory Instrument 265 of 2002. Zimbabwean Government Gazette.1313-1324.

9. Washi S Awareness of food labelling among consumers in groceries in Al-Ain, UAE. Int. J. Mark. Stud. 2012; 4(1):38-42.

10. Peterman $\mathbf{M}$ and TP Žontar Consumer Information and Labelling. In: Motarjemi Y and H Lelieveld (Eds).Food Safety Management: A Practical Guide for the Food Industry 2014:1005-1016.

11. Levy L, Patterson R, Kristal A and S Li How well do consumers understand percent daily values on food. Am. J. Health Promot.1999; 14(3): 126-128.

12. Grunert KG, Wills JM and L Fernandez-Celemın Nutrition knowledge, and use and understanding of nutrition information on food labels among consumers in the UK. Appetite J. 2010; 55:177-189.

13. http://www.foodstandards.gov.au/whatsinfood/foodlabeling.cfm $\left[\right.$ Accessed $27^{\text {th }}$ February 2014].

14. Berning JP, Chouinard HH, Manning KC, McCluskey JJ and DE Sprott Identifying consumer preferences for nutrition information on grocery store shelf labels. Food Policy 2010; 35: 429-436. 


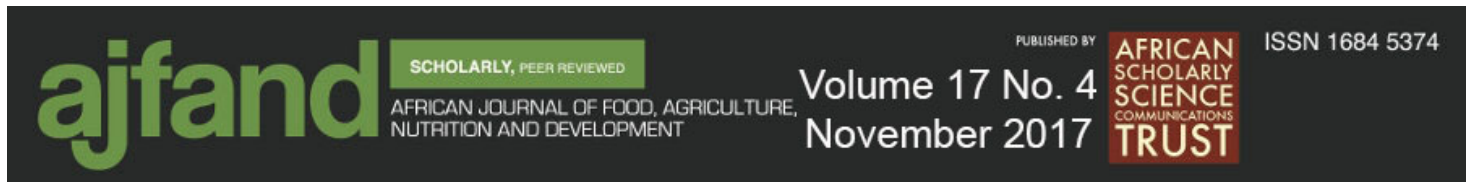

15. Drichoutis A, Lazaridus $\mathbf{P}$ and RM Nayga Nutritional knowledge and consumer use of nutritional labels.Eur. Rev. Agr. Econ.2005; 32(1): 93-118.

16. Grunert KG Food quality and safety: Consumers' perception and demand. Eur. Rev. Agr. Econ. 2005; 32(3): 369-391.

17. Rodríguez EMM, Beatriz L and VM Lacaze Consumers' perceptions about food quality attributes and their incidence in Argentinean organic choices. $J$. Agr. Sci. Tech. 2006; 1:375-385.

18. Stewart H, Blisard $\mathbf{N}$ and D Jolliffe Do Income Constraints Inhibit Spending on Fruits and Vegetables Among Low-Income Households?" J. Agr. Resour. Econ.2003; 28(3):465-480.

19. http://www.foodinsight.org/How consumers feel about food and nutrition m essages [Accessed 27th February 2014].

20. http://www.foodstandards.gov.au/mediareleasespublications/publications/Foodl abelingissuesquantitativeresearchconsumerjune2003/part/executivesummary [Accessed 27th February 2014].

21. Jacobs SA, de Beer $\mathbf{H}$ and $M$ Larney Adult consumers' understanding and use of information on food labels: a study among consumers living in the Potchefstroom and Klerksdorp regions, South Africa. Public Health Nutr. 2010; 14(3): 510-522.

22. http://www.which.net/campaigns/foodlabelling [accessed 27th February 2014].

23. Wandel $\mathbf{M}$ and A Bugge Environmental concern in consumer evaluation of food quality. Food Qual. Pref. 1997; 8(1): 19-26.

24. Nayga J Nutrition Knowledge, Gender and Food Label Use. The J. Cons. Aff. 2000; 34 (1): 97-112.

25. Beck U Risk Society: Towards a New Modernity, London, Sage Publications 1992:19-50.

26. Mahgoub SE, Lesoli PP and K Gobotswang Awareness and use of nutrition information on food packages among consumers in Maseru (Lesotho). Afr. J. Food Agric. Nutr. Dev.2007; 7(6): 1-14. 